\title{
As práticas de formação entre capturas e fugas na busca de um comum$^{1}$
}

\section{Marisa Lopes da Rocha}

Universidade do Estado do Rio de Janeiro, Rio de Janeiro, RJ, Brasil

Entre tantos possíveis de entrelaçar o coletivo e o individual nas práticas de formação, pensei em fazê-lo por duas aproximações: pelo exercício da prática profissional dos psicólogos na educação, e associando os encontros entre esses atores com os ensaios de uma orquestra de jazz a partir das contribuições de Amy Begel².

\section{Como podemos pedir} emprestado um pouco da liberdade e do espírito da música que chamamos jazz, pergunta Amy Begel (2004, p.45)? O Jazz surge no sul dos EUA, no início do século passado, fruto de uma mistura de raças e melodias que por meio de uma banda interpreta e improvisa harmonias - algo que vai emergir no conjunto. $\mathrm{O}$ que podem esses "especialistas musicais" ensinar sobre a experiência de uma prática de cuidados, de uma clínica institucional?

Como conectar uma sessão de jazz e um encontro de trabalho na escola, em uma conversa entre educadores? Falo em escola porque é onde normalmente desenvolvo minhas pesquisas, contudo poderíamos estar mudando os atores se falássemos em hospitais, postos de saúde, conselho tutelar...

Inspirada em Amy Begel, pensamos que a tensão da expectativa que caracteriza a sessão de jazz (p.45) também está presente no encontro de um especialista que é chamado para resolver algo/atender a uma instituição, e que envolve o cuidar e possíveis mudanças em modos de funcionamento para os quais não temos fórmulas.

Vou desenvolver esta apresentação em 3 pontos:

$1^{\mathrm{o}}$ ponto a considerar é a arte de improvisar, e isso significa que todas as nossas experiências, nossos saberes estão presentes num encontro, mas não como um bloco fechado a ser passado/ensinado ao outro. Trazemos para os novos trabalhos, para o território de nossas pesquisas tudo o que vivemos e pensamos ao longo de nossa formação porque nos constituímos nesse percurso. Não basta dominar uma técnica e ter um reservatório de respostas bem sucedidas, produzidas em atividades anteriores, para que possamos ensaiar a 
construção de redes. É uma questão de atitude no trabalho, na pesquisa. Em solos áridos não é fácil fazer ligas potentes e nossas ferramentas estão nas habilidades que vamos desenvolvendo para abrir espaços de arejamento, buscar um comum com o outro, espaço/tempo de coengendramento, de criação, de intensificação da vida onde ela insiste.

Diriamos, então, que a improvisação tem início quando aceitamos o desafio de novos encontros, artes de transversalizar histórias o que envolve lutas pelo próprio equilíbrio que não é estático, mas uma conquista permanente, uma vez que se produz no jogo de forças. Precisamos estar atentos porque a linguagem... não relata coisas simplesmente, ela faz coisas acontecerem, diz Begel (p.45). No momento em que alguém se dirige a mim já vai relatar/fabricar um "fato psicológico".

Neste sentido, a Análise Institucional nos ajuda com o conceito de demanda que fala do sofrimento que gera um pedido, mas um pedido feito para alguém (demanda é uma boa mistura de expectativas que se tem do outro, do desfecho de uma questão, de condições, de circunstâncias que inclui, no caso da escola, a formação de professores, de especialistas, do uso do tempo...). A demanda não carrega uma essência isolada que brota do "interior de alguém", ela emerge em meio às forças, em um conjunto de fatores, e por isso a importância de análise $d a$ demanda.

Quando chegamos a uma escola ou a qualquer instituição, já estamos comprometidos com a produção que ali se faz na solicitação de cuidados (não somos neutros).

A ideia que temos de que cada um é "um em seu lugar" e que o coletivo é "um outro", unidades isoladas ou agrupadas, começa a ser tensionada. Nossos lugares são construídos em conjunto, assim como as cenas que emergem no cotidiano - alguém fala algo a alguém que por sua vez responde em uma direção de escuta possível vamos compondo uma rede social atravessada por múltiplas forças:

. expectativas a priori de papel de uns em relação aos outros;

- reações, afetos, pensamentos que entram em cena;

- normas das instituições que são faladas, não faladas, habituais, tradicionais, metas;

. ambiente daquele(s) momentos(s);

- urgências, usos do tempo e do espaço....

O que queremos sublinhar é que cada um de nós vai produzindo um lugar nessa rede com o(s) outro(s) - o 
individual é um modo possível de expressar o que se passa (de ser/viver/fazer). Cada um de nós com o que traz, com o que dispõe é um múltiplo e vai tecendo o coletivo, a si próprio, ao outro...

Voltemos às experiências de Begel e aos músicos de jazz para quem o formato de uma sessão é sempre imprevisível, é no ensaio que as composições vão se fazendo e isso é parte da formação músicos. Formação que nunca se faz de uma vez por todas, não há a expectativa "individual”, "em si” de que aprendi a tocar, agora é executar para o outro ouvir e isto porque eles só tocam com o outro de modo que, mais do que cada um o que vale é um "entre".

Social não é o que está fora de nós, mas entre nós e que nos constitui, nos afeta.

A arte para os músicos do jazz está no encontro, no toque - tocar para se tocar, tocar para trocar ideia, aprender, divertir-se. Quando se encontram pela primeira vez, diz Begel, é um desafio de aceitação, de exploração e de experimentação em que o erro, as desafinações estão incluídas - a questão é aproveitar a oportunidade para o músico descobrir sua voz (p.45), seu tom em sintonia com o outro ao ouvir os demais músicos.
Com Passos \& Eirado (2009) diríamos que é preciso inverter o paradigma de conhecer para cuidar em cuidar como única forma de conhecer (p.122) - cuidar ou é uma tarefa conjunta, entre pessoas que criam lugares de fala e acolhimento de si e entre si ou não é.

$2^{\circ}$ ponto é o Não saber de Anderson \& Goolishian (1998). Segundo os autores é o cultivo da atitude do não saber que desconstrói a segurança de tudo saber, de uma identidade cristalizada, de nossa surdez para o imprevisível, ampliando nossa visão como ferramenta de um sensível que faz liga e inicia a tessitura com o outro. Nessa 4 perspectiva, é que se dá ao mesmo tempo um coletivo (entre, comum) e cada um de nós, remexendo na nossa história, na nossa formação a favor do encontro.

A posição do não saber tensiona o dualismo especialista-comunidade em que ninguém tem a priori acesso a um conhecimento privilegiado, pois terá de ser produzido a partir do que se tem, estando todos os atores sempre em posição de serem informados, lugar de curiosidade, de atenção ao outro e da análise contínua das experiências-limite. $\mathrm{O}$ que se passa e o campo de escolhas que emerge no entre constitui nossas práticas, práticas de si sempre 
provisoriamente. Isso significa que esse processo requer prudência como diria Deleuze \& Guattari (1996). Isto requer:

. não entender rápido demais;

- estar disposto ao risco, não há um lugar de segurança;

- deixar que as narrativas ganhem consistência entre o maior número possível de atores para que a rede seja mais suave, porque dividida, compartilhada, e mais forte para sustentar análises, vulnerabilidades e riquezas;

- deslocar-nos (nossa escuta é seletiva como as demais... vimos de uma formação dura e fragmentada) porque, via de regra, entramos nas instituições para mudar os outros, os que supostamente não sabem. Território endurecido em que as posições estão há muito estabelecidas: "eu", "você", “o coletivo" (um monte de eus "em si") tudo segmentado.

Então, melhor do que termos boas ideias é o que fazemos com elas. Talvez, mais um pouco de jazz nos ajude.

Nas sessões de jazz não têm programas estabelecidos ou repertório... pois isso subestima a tensão da exigência de técnica musical apurada (Begel, 2004, p.45) ao mesmo tempo que atenua o desafio da inventividade. Ou seja, não se trata de não estudar, de fazer qualquer coisa..., pelo contrário, é preciso criar com o outro um campo de experimentação e isso nos exige cada vez mais um domínio acurado da técnica para ousar novos acordes produzidos em conjunto, procurando o tom (estilo). A questão é sustentar uma conversa para descobrirse nas ações - os músicos especialistas se deslocam, se procuram no ritmo.

Podemos considerar que aprender a improvisar e a sustentar a tensão enquanto uma atitude política é também:

- considerar que a invenção musical oferece aos músicos de jazz a oportunidade única de autoexpressão e isso implica em correr risco, verificar o que funciona ou não, o que flui ou não, sentir-se confortável em "não saber" uma vez que suas notas musicais são desenvolvidas à medida que a canção se cria (p.46);

. desejar o improviso para entrar com os ouvidos atentos e experimentar vias de acesso à rede que tensiona/questiona a rotina, acolhendo a ansiedade/pressão por respostas, na luta pela liberdade de não ter que "resolver" as questões produzidas no jogo institucional da individualização que mantem o que está edificado de pé;

- afirmar que nosso trabalho em saúde é escapar do aprisionamento que adoece: 
medo, ansiedade, sentimentos de incompetência, queixas..., fazendo cada um de nós e os demais de sentinelas que intimidam a vida.

$\mathrm{O}$ que afeta nossos colegas (o que nos afeta!) para fazer de suas (de nossas!) técnicas e conhecimentos, já vividos/produzidos, um novo campo de experimentação que dê passagem a acontecimentos?

Com Begel vemos que:

Os instrumentos tipicamente presentes numa sessão de jazz incluem piano, baixo e bateria, chamados de sessão rítmica, além de qualquer número de instrumentos de sopro, notadamente o saxofone e trompete. Os instrumentos de sopro são considerados solistas, os primeiros a improvisar ao final da execução da melodia.... quando terminam a improvisação - o piano e o baixo podem solar, às vezes trocando ou alternando-se em alguns compassos com a bateria. (p. 47)

É importante perceber que, quando um instrumento está solando, "falando" os demais mantém o ritmo, dando suporte musical, energia ao solo e buscando não interferir, contudo favorecendo uma escuta sensível que alonga e aumenta o som de algumas notas que podem sugerir outras direções. Músicos de jazz desejam conversar entre si na linguagem da música. Isso significa que têm que ouvir, interagir e tocar ao mesmo tempo (p.47).

Mas no jazz você precisa ser gentil. Isto quer dizer não tocar muito alto, e não tocar tanto a ponto de atravessar a atuação dos demais (p.47). É um campo sensível. Por ser o jazz uma forma de arte humana, algumas vezes atravessamos o compasso e irritamos os demais músicos. Isto acontece com tipo de pianista que, em vez de ouvir e receber a orientação musical de outros músicos insiste ou impõe seus pensamentos musicais...(p.47).

Este é o homem moderno-emnós que se entende como alguém que tem competência, capacidade e qualidade "dentro de si mesmo" como uma essência que carrega, entendendo coletivo como um conjunto de pessoas fragmentadas e hierarquizadas. É aí que falamos no dualismo particularidadetodo, de padrões e de "boas" formas, de existência na previsibilidade.

Nesse pensamento não vemos os professores, as crianças, as famílias, os loucos... como um processo que se singulariza entre nós ganhando contornos, constituindo subjetividades nas situações em que vivem - nos coletivos das práticas e afetos em que existem e fazem existir a vida na 
profusão de interferências, respostas, atravessamentos.

No modelo médico-assistencial em que nos formamos, frequentemente sofremos e fazemos sofrer os atores com quem trabalhamos porque acreditamos que nossa atuação é mais como solista do que como o pianista que atua em continuidade com as ideias e o sentimento dos músicos... dos professores, das famílias, dos jovens. A tendência de nosso referencial é considerar que o mérito profissional se baseia na liderança, eficiência e mérito que significam saberes impostos aos outros. Falamos demais e, quase sempre, parece que mais esforços foram gastos do que os resultados esperados na criação de diálogos.

Temos tentado atuar de forma a complementar os colegas para engajálos nas buscas, ensaios, discussões, convidando-os para solar?

São as relações de convivência, que podem agenciar um plano de forças que compõe um comum em que pesquisadores, especialistas, professores, administradores, pais e alunos se constituem e constroem acordos possíveis a cada vez. Peter Pelbart (2008) afirma que este comum é o visado pelas capturas e sequestros capitalísticos, mas é igualmente esse comum que os transborda, fugindo por todos os lados.

$3^{\circ}$ ponto é onde evidenciamos que Não basta dar a palavra, como diz Guattari (1973, citado por Lourau, 2004, p. 66), pois é preciso mais que técnica para criar dispositivos que desconstruam a montagem hegemônica que nos atravessa a todos. Dizemos que não é só técnica porque as relações humanas requerem as artes de viver, as políticas do conviver. Às vezes a equipe da instituição ou a família ou o colega especialista está tocando um pouco mais longe ou um pouco mais forte e apenas tentar ouvir já é estratégico, não para uma dissonância raivosa, evidencia Begel (2004, p. 48), porém para tentar um campo de análise do que está em jogo, do que está em cena. Isso é importante se queremos escrever a história que vai ganhando corpo com o outro.

Assim, cuidar requer a disposição para o aprendizado de coisas novas, para a compreensão de histórias sem determinação de causalidades apriorísticas do que escapa à média, para atenção às circunstâncias de emergência de um acontecimento, plano de composição do que pode fazer sentido. Cuidar requer tática para a mobilização de hábitos que tecem cada um de nós nas relações - somos um 
dobrar e desdobrar permanente das forças que compõem o coletivo e que na experiência favorece a construção de um lugar a cada vez, o descobrir da minha voz (p.49).

Lembrando que "Não saber" como pontua Derrida (1998), não significa que não conhecemos nada, mas que a produção de conhecimento se dá na relação que estabelece condições e lugares, abertura de espaço para o outro solar suas histórias.

Com Begel, vemos ainda que, quando o especialista avança para soprar (solo), ele e os atores do campo já estão dançando juntos (p.48), conectados no ritmo do ouvir (do sustentar a ansiedade das urgências) para tocar jazz como banda, permitindo aos músicos se colocarem no samba? Bossa nova? Funk? E isso pode mudar e variar durante o curso da música (p.48), atenção ao convite, pois a combinação entre estabilidade e movimento aumenta o prazer entre os músicos e aí não importa quem iniciou a melodia. O fundamental é que, a cada momento, possamos estar ligados na cadência que faz sentido entre $o$ individual e coletivo: busca do comum.

\section{Notas}

1 Palestra conferida na Aula Inaugural do PPGPSI/UFRGS, 2012.
2 Amy Begel é terapeuta de família, pianista e cantora amadora de jazz, autora do artigo "A sessão da família - uma sessão de jazz", publicado na Revista Nova Perspectiva Sistêmica, Ano XIII, n. 24, 2004 (trad. Maria Regina da S. Ferreira do original "The Family Conference: A Jazz Jam", publicado em Families, Systems \& Health 16 (4), pp. 437-442, 1998).

\section{Referências}

Anderson, H. \& Goolishian, H. (1998). O cliente é o especialista: a abordagem terapêutica do NãoSaber. Em S. McNamee \& K. Gergen (Orgs.), Terapia como construção social (pp.34-50). Porto alegre: Artes Médicas.

Deleuze, G. \& Guattari, F. (1996). Mil Paltôs. Capitalismo e esquizofrenia, Vol 3. Rio de Janeiro: Ed. 34.

Derrida, J. (1998). Politicas de la amistad. Madrid: Editorial Trotta.

Guattari, F. (1973). Liminaire de Recherches, citado por R. Lourau no texto Objeto e método da análise institucional. Em S. Altoé (Org.), René Lourau. Analista Institucional em tempo integral, 
(pp. 66-86, 2004). São Paulo:

Hucitec.

Passos, E. \& Eirado, A. (2009).

Cartografia como dissolução do ponto de vista do observador. Em E. Passos, V. Kastrup \& L. Escóssia (Orgs.), Pistas do método da cartografia (pp.109130). Porto Alegre: Sulina.

Pelbart, P. P. (2008). Elementos para uma cartografia da grupalidade. Em F. Saadi \& S. Garcia. (Orgs.), Próximo ato: Questões da Teatralidade Contemporânea. (pp. 33-37). São Paulo: Itaú Cultural 